\title{
Numerical and Experimental Study on the Locally Blast Loaded Polyurea Coated Steel Plates
}

\author{
FLORINA BUCUR, EUGEN TRANA, ADRIAN ROTARIU* \\ Military Technical Academy Ferdinand I, 39-49 G. Cosbuc Av., Bucharest, Romania
}

\begin{abstract}
The damages and casualties inflicted by mine and IED attacks in security challenging areas generated a strong and quick response from nations all over the world. As a part of this response several national and private research facilities increased their efforts in identifying and implementing new ways or technologies to enable blast wave mitigation. The current paper aim to investigate the opportunity of using polyurea coated steel plates as a possible new blast mitigation approach, as suggested by several investigators. In order to objectively conclude about the ability of polyurea coated plates to sustain locally blast loads several experimental tests were performed according to STANAG 4569 demands for a 1/6 scaled plate structure. In order to numerically validate the experimental results several Autodyn simulations were set-up. The numerical and experimental results exibits a fair correlation, both pointing towards a dismiss of the idea of using polyurea coated steel plates as structural and cost effective blast mitigation approach.
\end{abstract}

Keywords: coated metal plates, polyurea layer, blast load, numerical simulation

Blastloading research for ballistic protection evaluation of structures and the development of blast-proof materials have been in progress over the last decades. The respons of multilayer structures of polymer/metal type, subjected to impulsive loads, is one of the studied topics.

The research regarding implementation of polymeric materials in civilian and military application is in full development nowdays, due to their proven superior mechanical properties, viscolelasticity and hyperelasticity and low cost price. A survey in scientific literature emphasizes that the most used and tested technical polymer with significant results is polyurea. By its simple way of deposition, it forms a $100 \%$ solid, continuous and waterproof film with no harmful effect on the environment and with high thermal resistance compared to other technical elastomers [1, 2].

The scientific literature contains a series of experimental studies regarding the use of polyurea to improve the existing structures properties, especially to increase the blast and impact proof protection of buildings, vehicles and personnel [3-7].

As long as such structures include materials of highly different mechanical properties, the development of analytical models, based on simplification assumptions, to better understand global respons of the structure may provide unsatisfactory results, which implies necessity to develop empirical relations that match the cause (i.e. impulse loading) with the effect (i.e. produced deformation).

An alternative at hand to understand and assess the modification of the complex structures response is numerical approach, where the structure and the adiacent loading medium are discretized and associated with specific constitutive laws [8-10].

The polyurea specific law is obtained through a number of mechanical experiments at low and high deformation rates [11]. These experiments have shown that the polyurea exhibits elastic and almost incompressible behavior and its stress-strain response is largely depending on deformation, temperature and pressure [6]. Experimental studies (uniaxial tension or compression) have been made for a range of strain rate between $10^{-3}$ -
$6000 \mathrm{~s}^{-1}[6]$. The most accessible model proposed for the polyurea, valid for a large (wide) range of deformation rates, is a nonlinear viscoelastic model based on two dependent functions: the deformation-dependentfunction described by the Mooney-Rivlin model, and the timedependent behavior described by the Prony series [12] The specific stress-strain curves show a strong strengthening trend, only after the deformation reaches $100 \%$ [11], a value unattainable for most of the steels in uniaxial load.

Anyway, for ductile soft metals coated with polyurea, a delay of necking was observed, a prove of its capability to improve the energy absorption and dynamic performance of structures, fact experimentaly and numericaly demonstrated by test with SHPB and blast tests [13-15].

Lab tests on small plates uniformly loaded show that at the energy level that produced catastrophic fractures in armor steel, plates coated with polyurea resist without any fracture, even if the mass added is less that $10 \%$, and the polyurea layer is added to the face subjected to blast load [16]. Regarding the position of layer, better results were obtained when polyurea layer was coated on the back side on structure subjected to dynamic or impulsive loads [17].

In a more recent study, reference and coated mild steel plates were exposed to blast load in range tests at the levels that do not produce necking of the plates. Measuring the permanentmaximal deflection and using the proposed assessment formulas, there was observed that the effect of polyurea coating on the applying pressure face is strongly dependent on the stand-off, more exactly at lower standoff distance the polyurea layer proved to be less effective [18].

The current paper aims to analyse the behavior of steel/ polyurea plates by experimental and numerical tests.

The experimental program consists of small scale blast loads tests on reference and polyurea coated plates (on one of the sides) with explosive charge in close proximity of the plates. The organisation and the tests conducting, the experimental measurements and post-test evaluation of the results are presented gradually.

Furthermore, we analyse the effect of elastomer coats on the impulsive behavior of the steel plates in the bilayer configuration by numerical means, namely by building

\footnotetext{
* email: adrian.rotariu@mta.ro
} 
virtual models in AUTODYN $®$. Several specific aspects that affect the numerical model accuracy, like test rig and plates discretisation solution, polyurea constitutive model, REMAP techniques, Euler/Lagrange interaction, and gauge definitions are addressed.

In discussion section, the efficacity of the polyurea layer is assessed through relevant formulas and a comparison between experimental and numerical results.

\section{Experimental part}

\section{Materials and experimental set-up}

The experimental tests were conducted in an open army shooting range on a small-scale test rig in order to evaluate the effects of an additional polyurea layer on the local and global behavior of a metal structure that simulate a vehicle belly subjected to a mine blast. The final dimensions for studied configuration resulted from the scaling process (1/ 6 scale) are $1000 \mathrm{~mm} \times 200 \mathrm{~mm}$ for plate dimensions and a total mass of $50.85 \mathrm{~kg}$ for test rig.

Three types of plates were tested: $2 \mathrm{~mm}$ thickness bare plates as reference and coated plates on inside or outside. For the steel plates an 0 $\mathbf{5 0}$ steel with $342 \mathrm{~N} / \mathrm{mm}^{2}$ yield stress, $21 \%$ fracture elongation and $7.81 \mathrm{~g} / \mathrm{cm}^{3}$ density was used. This relatively soft steel with small yield tension value was chosen to ensure a larger deflection of metal plates. For the polymer layer a quantity of $400 \mathrm{~g}$ polyurea was sprayed on each side of steel plate. A $1.1 \mathrm{~g} / \mathrm{cm}^{3}$ density polyurea layer (EUROPOL $®$ ) with $2 \mathrm{~mm}$ thickness and $180 \mathrm{~mm}$ width was used. Two lateral narrow bands of 10 $\mathrm{mm}$, close to the bent edges of plates, remained uncovered by polyurea (Fig. 2b). The plates were attached to the reutilisable rig by two lateral rows of fastners. The polymer layer brings an areal density increase of $12.67 \%$.

As explosive charges, cylindrical blocks of $30 \mathrm{~g}$ of $\mathrm{C} 4$ plastic explosive were prepared. The charge quantity was calculated based on the scaling law, and replaces the surrogate charge of $8 \mathrm{~kg}$ TNT (level III [19]). The scalled reutilisable steel pot with the explosive charge encapsulated in a polystyrene shell was placed on the soil surface under the structure center, at a scaled ground clearance of $141.6 \mathrm{~mm}$ (Fig. 1). The charge detonation was initiated by an electrical detonating blast cap inserted in charge through the steel pot central hole.

The test rig was accesorised in order to record overpressure, acceleration and transmitted pulse to structure. For test recording, a measure chain was used: a pressure transducer (PCB 102B06) mounted in a face-on position (the sensitive transducer surface is positioned parallel to the blast wave front for the measurement of overpressure that is transmitted behind the witness plate), a second pressure transducer (PCB 102B04) mounted in a side-on position above the center of the plate and an accelerometer (PCB 350B21) mounted on the testrig edge in the center on the lateral side.

For recording the experimental tests, a PHOTRON high speed camera located at a $15 \mathrm{~m}$ distance from the test site and an acquisition data system, PicoScope ${ }^{\circledR} 6$, were used.

All data recorded and saved through the acquisition software, were analyzed and processed. The experimental test set-up overview is depicted in figure 1.

A number of seven tests were performed as follow: three tests for witnees-plate (reference plate), two tests on bilayer plate with back coated polyurea (opposite side of plate) and two tests on bilayer plate with front coated polyurea (in direct contact with the explosion front). Data acquired by accelerometer and pressure transducer were recorded to be analyzed and further processed. Each channel had independent trigger. Acceleration signals were processed using Mathcad software. The evolution of the structure ascending velocity by integrating acceleration signals was calculated. Each performed test was recorded with high speed camera.

After performing the tests, it was analyzed in which manner the plates were affected by the impulse transferred to structure. All tested plates presented deflection with a dishing pattern in central area, right above the charge. When polyurea layer was directlly exposed to detonation

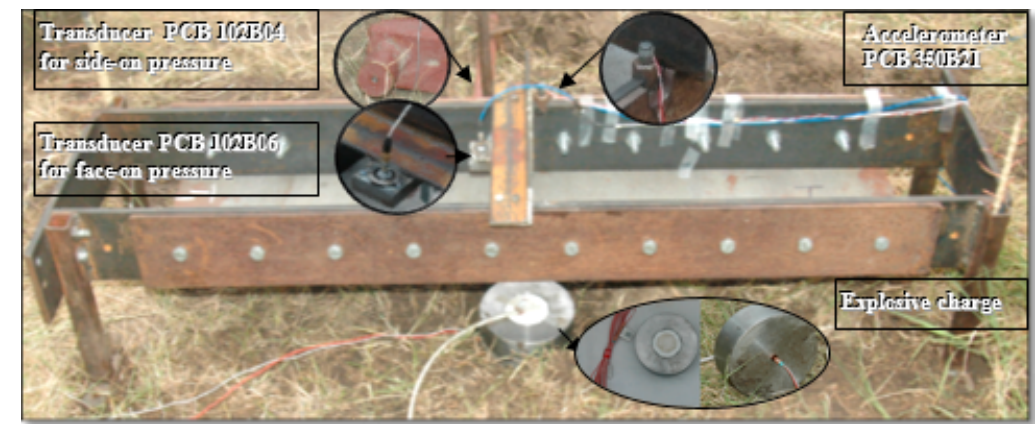

Fig. 1. Experimental set-upl

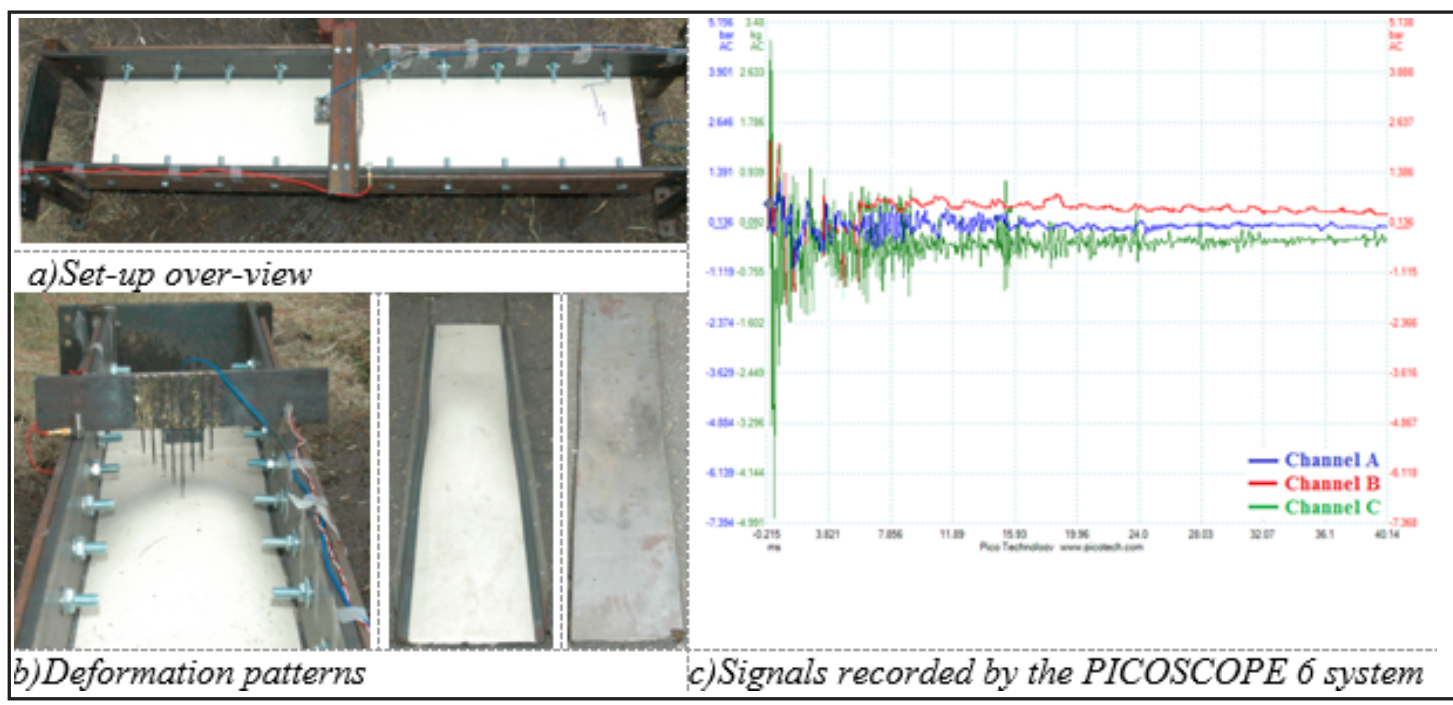

Fig. 2. Typical exemple of experimental data resulted from bilayer plate testing- back coated polyurea 
gases, a deterioration of the polyurea layer in the central area was observed. For each tested plate the maximum permanent deflection was measured. The impulse transmitted to rig was evaluated by meaning of images capturated by high speed camera. The measurements results and calculated data are presented in table 2. Typical exemple of experimental data resulted from bilayer plate testing are shown in figure 2 .

\section{Numerical modeling}

A further analysis of the interaction and effects of shock waves on experimentally tested structures was conducted using AUTODYN ${ }^{\circledR}$, a numerical modeling software.

The numericall approach consist in two steps. An initial axial 2D model was build only with the steel pot (Lagrange part) and the explosive charge and the surrounding air (Euler part). Such model, having a reduce number of elements of small dimensions, was able to reproduce with high fidelity the charge detonation and the shock wave propagation through air till the moment just before of the shock wave/structure interaction. According to standard procedure, the charge was bottom initiated. For the explosive charge an JWL (J ones-Wilkins-Lee) equation of state was used.

The shock wave/structure interaction imposes an 3D model. For the 3D model, a EULER space was defined and loaded with air atnormal atmospheric pressure. An uniform meshing technique for the $140 \times 400 \times 600 \mathrm{~mm}^{3}$ volume was used.

For the all metallic rig components the shell meshing option was choosed. The thickness for each component was defined according to the real dimensions. For the test plates uniform size quad elements of $5 \mathrm{~mm} \times 5 \mathrm{~mm}$ were used. Following the meshing procedure, 16,000 elements were resulted. The polyurea layer was modeled as Lagrange part with volume elements as long as the hyperelastic materials can not be associated with shell elements. For the meshing of the $2 \times 180 \times 1000 \mathrm{~mm}^{3}$ polyurea layer a total of 14,400 volume elements were created. The nodes joint option was used in order to model the polyurea layer attachment to the metallic plates. In a similar manner all the test rig components were joined together to behave as a single body.

On the plate and test bench, five virtual transducers were placed as shown in figure 3: two for measuring the velocity induced to plate by the shock wave $(2,4)$, two for measuring the overpressure $(3,5)$ and one transducer in plate for measuring the von Mises stress (1).

The material models used for the explosive, air, metallic plates, polyurea layer and rig components are presented in table 1.

AUTODYN ${ }^{\circledR}$ solver does not allow the input of the polyurea model parameters with Prony series experimentaly determined by Gamonpilas and Mccuiston

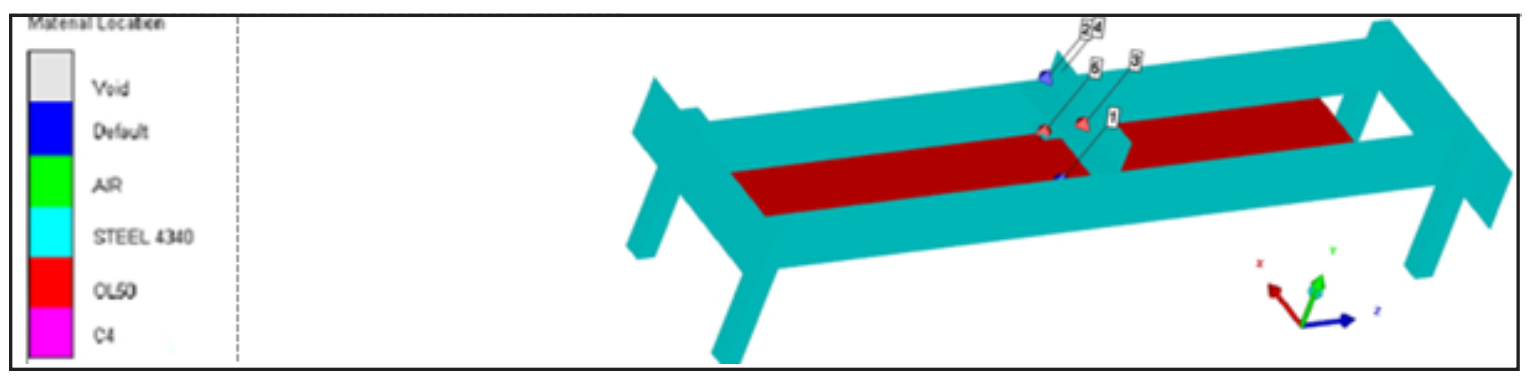

Fig. 3.

Experimental set-up and transducers location for standard plate testing

\begin{tabular}{|c|c|c|c|c|c|c|c|}
\hline \multirow{2}{*}{\multicolumn{3}{|c|}{$\begin{array}{l}\text { Material name } \\
\text { Reference Densitv }\left(\mathrm{g} / \mathrm{cm}^{3}\right)\end{array}$}} & AIR & $\mathrm{CA}$ & STEEL $4340^{\circ}$ & OL 50 & POLYRUBBER \\
\hline & & & 0.001225 & 1.601 & 7.83 & 7.81 & 1.1 \\
\hline \multicolumn{3}{|c|}{ Equation of state } & Ideal Gas & JWL & Liniar & Liniar & Hyperelastic \\
\hline \multicolumn{3}{|c|}{ Gamma } & 1.4 & & & & \\
\hline \multicolumn{3}{|c|}{ Reference Temperature $(\mathrm{K})$} & 288.200012 & & 300 & 293 & 293 \\
\hline \multicolumn{3}{|c|}{ Specific Heat (J/kgK) } & 717.599976 & & 476.99 & & \\
\hline \multirow[t]{5}{*}{ Parameters } & & Pa) & & $6.0977 \cdot 10^{8}$ & & & \\
\hline & & Pa) & & $1.295 \cdot 10$ & & & \\
\hline & $\mathrm{R}$ & & & 4.5 & & & \\
\hline & $\mathrm{R}$ & & & 1.4 & & & \\
\hline & $\pi$ & & & 0.25 & & & \\
\hline \multicolumn{3}{|c|}{ C-JDetonation Velocity $(\mathrm{m} / \mathrm{s})$} & & $8.193 \cdot 10^{5}$ & & & \\
\hline \multicolumn{3}{|c|}{ C-JEnergy $\left(\mathrm{kJ} / \mathrm{m}^{3}\right)$} & & $9.000001-10^{\circ}$ & & & \\
\hline \multicolumn{3}{|c|}{ C-JPressure (kPa) } & & $2.8 \cdot 10$ & & & \\
\hline \multicolumn{3}{|c|}{ Bulk Modulus (kPa) } & & & $1.59 \cdot 10^{8}$ & $1.75 \cdot 10^{8}$ & \\
\hline \multicolumn{8}{|c|}{ Strength Materials } \\
\hline \multicolumn{3}{|c|}{ Constitutive Model } & & & Johnson Cook & Johnson Cook & $\begin{array}{l}\text { Hyperelastic } \\
\text { Mooney-Rivilin }\end{array}$ \\
\hline \multirow[t]{5}{*}{ Parameters(kP) } & & $\mathrm{C} 10$ & & & & & $-4.2427 \cdot 10^{4}$ \\
\hline & & $\mathrm{CO1}$ & & & & & $6.1849 \cdot 10^{4}$ \\
\hline & & C11 & & & & & $-1.777 \cdot 10^{3}$ \\
\hline & & $\mathrm{C} 20$ & & & & & 257 \\
\hline & & $\mathrm{CO} 2$ & & & & & $1.4578 \cdot 10^{4}$ \\
\hline \multicolumn{3}{|c|}{ Shear Modulus ( $(\mathrm{kPa})$} & & & $8.18 \cdot 10$ & $8.08 \cdot 10^{\prime}$ & \\
\hline \multicolumn{3}{|c|}{ Yield Stress (kPa) } & & & $7.92 \cdot 10^{3}$ & $3.42 \cdot 10^{2}$ & \\
\hline \multicolumn{3}{|c|}{ Hardening constant $(\mathrm{kPa})$} & & & $5.1 \cdot 10^{2}$ & $3.005 \cdot 10^{2}$ & \\
\hline \multicolumn{3}{|c|}{ Hardening Exponent } & & & 0.26 & 0.24 & \\
\hline \multicolumn{3}{|c|}{ Strain rate constant } & & & 0.014 & 0.022 & \\
\hline \multicolumn{3}{|c|}{ Thermal Softening Exponent } & & & 1.03 & 1 & \\
\hline \multicolumn{3}{|c|}{ Melting Temperature (K) } & & & $1.793 \cdot 10^{5}$ & $1.811 \cdot 10^{3}$ & \\
\hline \multicolumn{3}{|c|}{ Refrerence Strain Rate } & & & 1 & 1 & \\
\hline
\end{tabular}

Table 1 MATERIAL MODELS FROM AUTODYN ${ }^{\circledR}$ LIBRARY [20] 
[1]. Due to this shortcome the coeficients of Mooney-Rivlin model were determined for a mean value of strain rate of $200 \mathrm{~s}^{-1}$.

The final step of the 3D model building consisted in data importing on Euler space from the axial 2D model at time $t=0.0289 \mathrm{~ms}$ through the REMAP option.

40 ms time spam for each simulation was set-up [21].

For the numerical simulation of the front coated polyurea plate subjected to blast load a problem of interaction has occurred between air defined as an Euler environment and polyurea layer of Lagrange type with elements of volume type.

If in the simulation of back coated polyurea, the interaction takes place between Euler elements and Lagrange shell elements, in the case of front coated polyurea, the interaction occurs between Euler elements and Lagrange volume elements.

For this simulation the results are significantly different from the other two test types simulated (reference plate and back coated polyurea plate) and the experiment. The impulse transferred to the structure increases with $75 \%$.

To eliminate the inconvenience of an unjustified increased momentum, we chose to cover the Lagrange discretization corresponding to the polyurea layer with a shell discretization of thickness and consistency of an aluminium $0.01 \mathrm{~mm}$ thickness foil shown in figure 4. At this thickness the foil has a negligible mass and do not affect the impulse transfer from the shock wave to the structure. For the aluminum model, the AL5083H116 material available in the AUTODYN ${ }^{\circledR}$ library was used. In the presence of the aluminium foil the impulse transferred to the structure reaches a level comparable to the other two modeled cases and experimental results.

The interaction between the incident shock wave and the test plate and the formation of the reflected wave in the central transversal section of all three tested configurations are depicted in figure 5.

The manner in which the shock wave acts on the test rig it can be observed from the data recorded with virtual transducers. The evolution of the recorded signals corresponding to the gauges position is shown in figure 6 .

Also, the global assessment of rig movement indicates that the momentum is transferred to the structure in the first $0.2 \mathrm{~ms}$ and that after $10 \mathrm{~ms}$ from the initial moment the velocity induced to test rig stabilizes and fits within an evolution controled by gravity, which means that the momentum transferred to the structure was distributed throughout the entire structure and plastic deformation of the tested plate stops.

AUTODYN ${ }^{\circledR}$ solver interface allows the extraction of relevant data on the interaction of shock wave with analyzed structures regarding the distribution of displacements, strains and stresses. The maximum equivalent plastic strainvalues on tested metallic plate in all three configuration after $\mathrm{t}=40 \mathrm{~ms}$ is highlited in figure 7.

\section{Results and discusions}

The first observation on the experimental results refers to the consistency of the measured data. Except the test

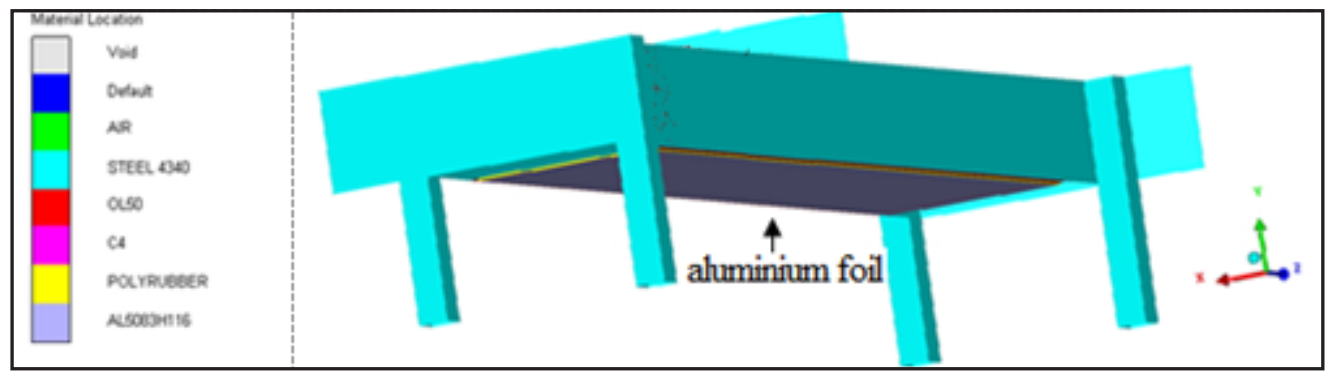

Fig. 4. Test stand and location of transducers for front coated polyurea

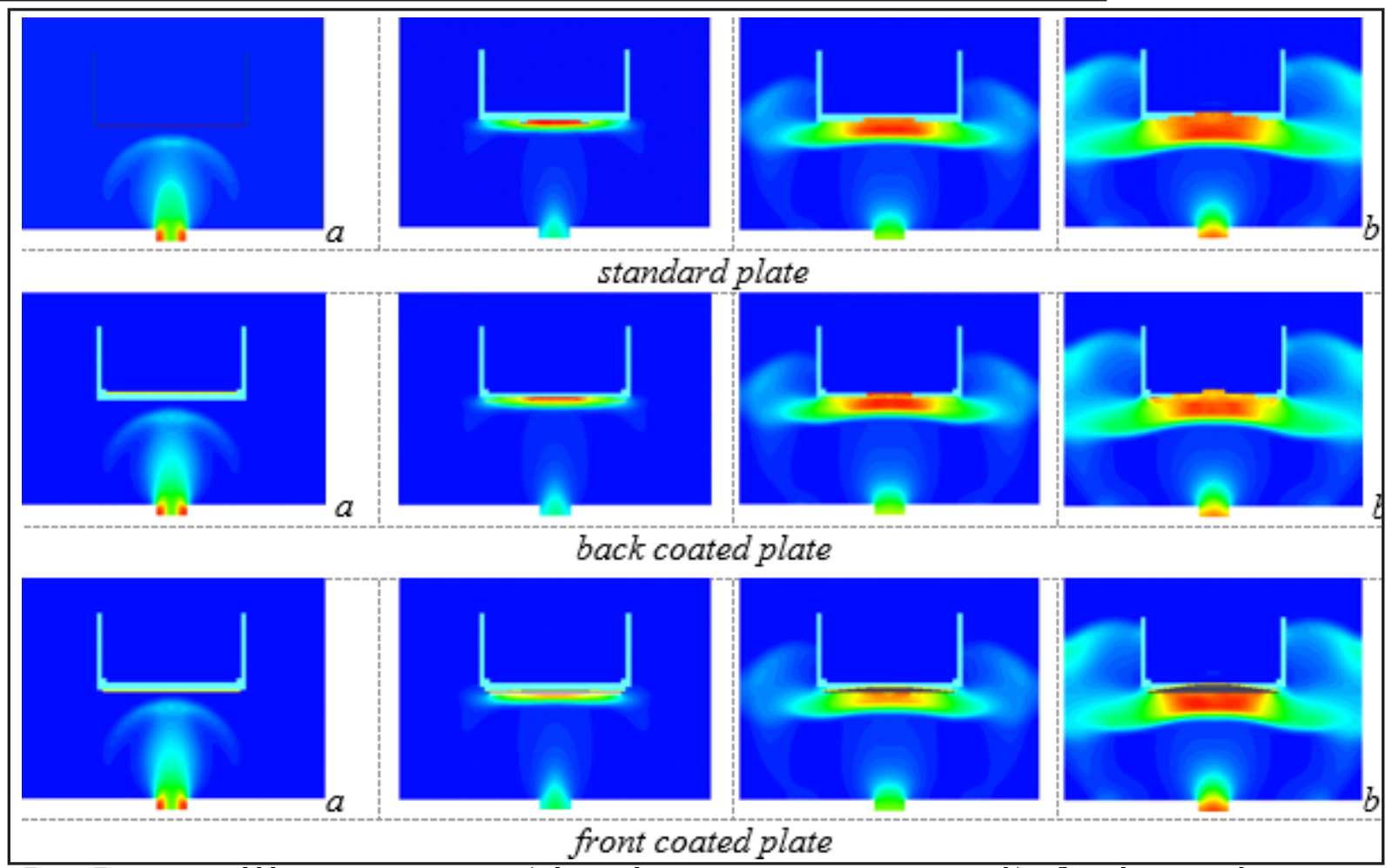

Fig. 5. Formation and blast wave propagation: a) the incident wave position at time $\mathrm{t}=0 \mathrm{~ms}, \mathrm{~b})$ reflected wave at plate impact at $\mathrm{t}=0.02 \mathrm{~ms}, \mathrm{t}=0.05 \mathrm{~ms}$ and $\mathrm{t}=0.07 \mathrm{~ms}$ in $3 \mathrm{D}$ mode 


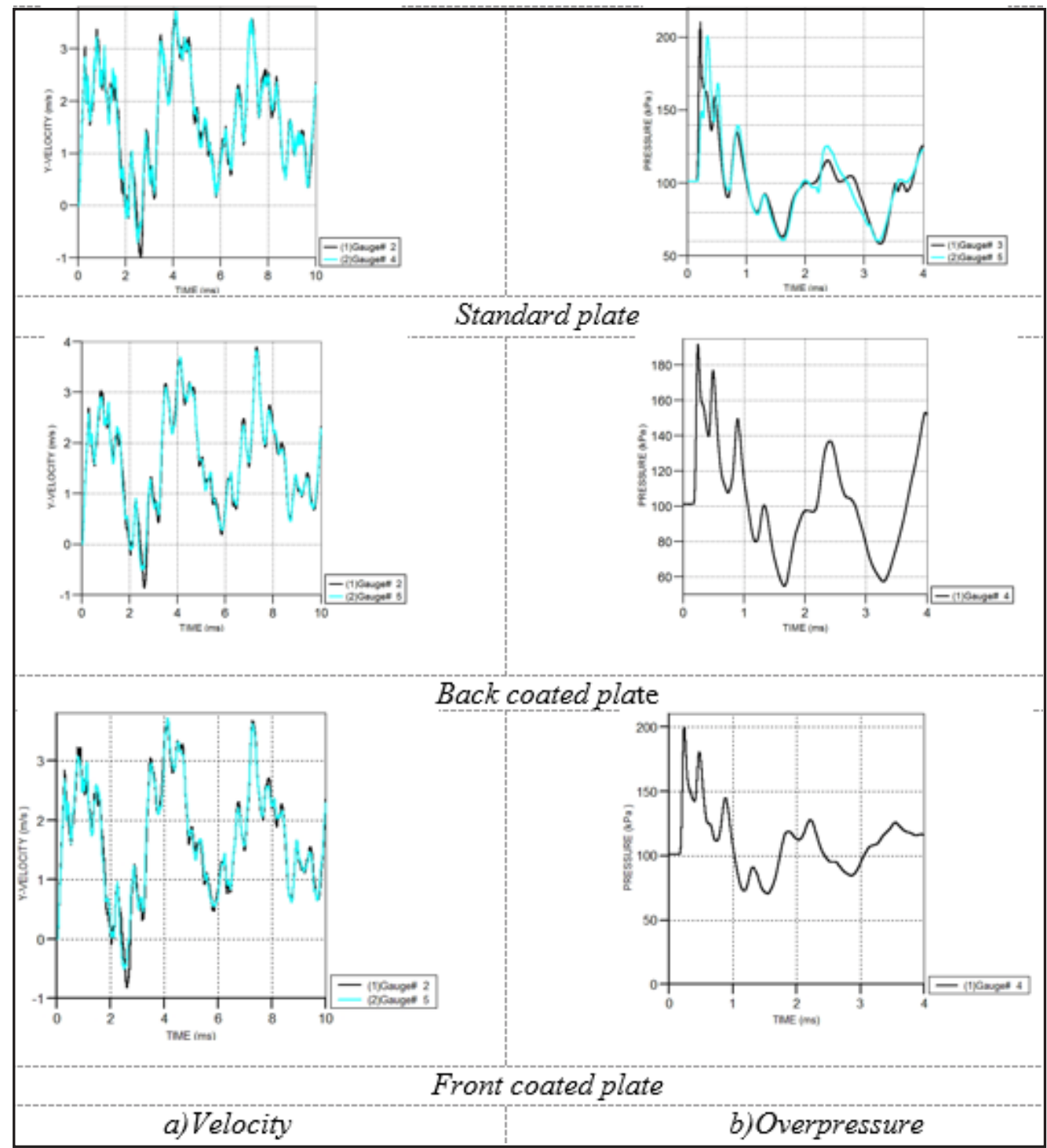

Fig. 6. The evolution of the parameters recorded by virtual sensors

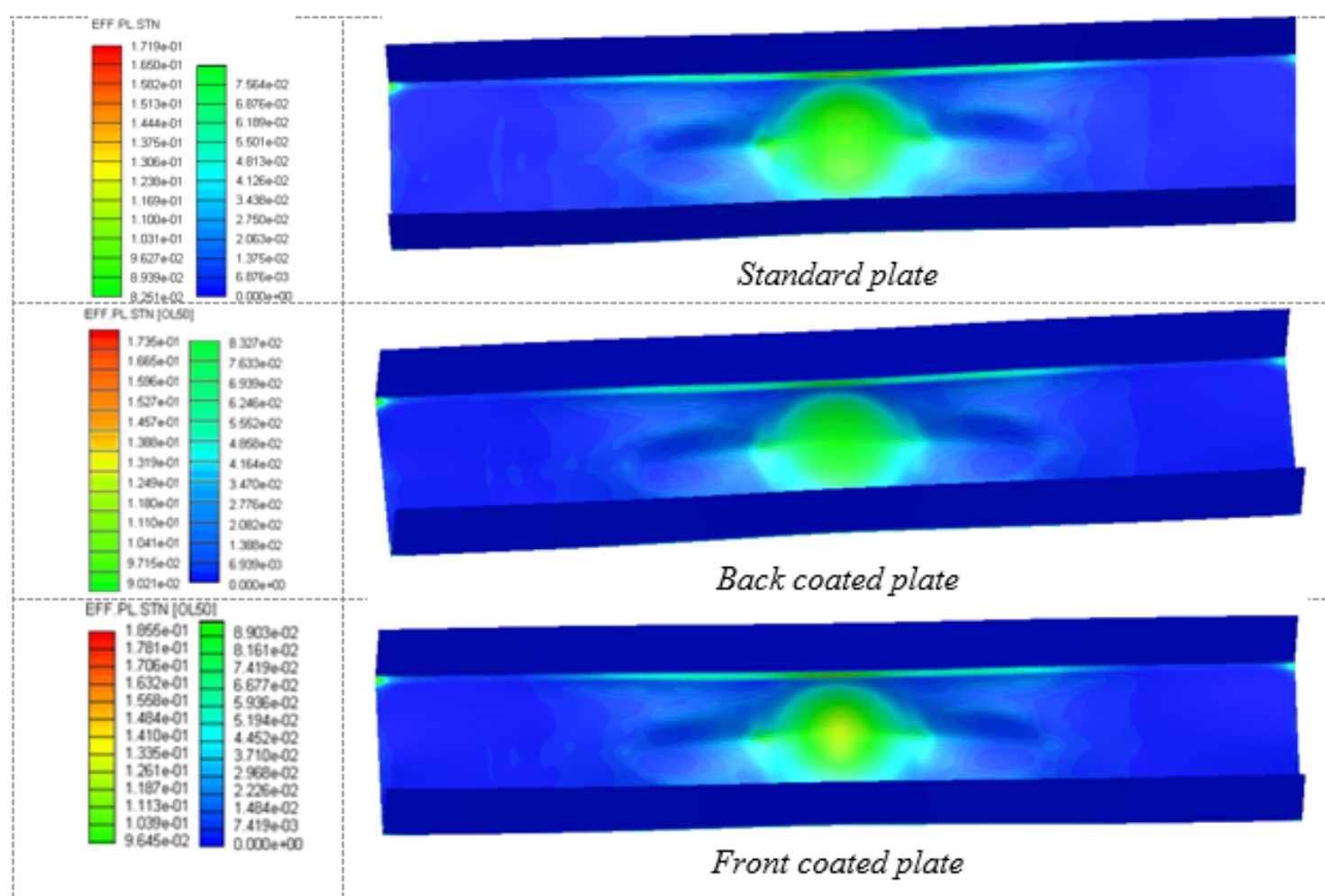

with front coated plate, the transferred momentum show a good constintency even if for the coated plates it seems to be slighty higher. The exception can not be seen as an mitigation effect of the polyurea layer as the other test do
Fig. 7. Iso-values of effective plastic deformation at $\mathrm{t}=40 \mathrm{~ms}$ 


\begin{tabular}{|c|c|c|c|c|c|c|c|c|}
\hline \multirow[b]{2}{*}{$\begin{array}{c}\text { Tested } \\
\text { configurations }\end{array}$} & \multicolumn{4}{|c|}{ Experimental test } & \multicolumn{3}{|c|}{ Numerical simulation } & \multirow{9}{*}{$\begin{array}{c}\text { Table } 2 \\
\text { COMPARATIVE } \\
\text { ANALYSIS OF THE } \\
\text { MAIN RESULTS } \\
\text { OBTAINED }\end{array}$} \\
\hline & $\begin{array}{l}\text { Test } \\
\text { no }\end{array}$ & $\begin{array}{c}\text { Permanent } \\
\text { deflection } \\
\text { (transversal) } \\
(\mathrm{mm})\end{array}$ & $\begin{array}{l}\text { Initial } \\
\text { Speed } \\
(\mathrm{m} / \mathrm{s})\end{array}$ & $\begin{array}{c}\text { Momentum } \\
\text { transferred } \\
(\mathrm{kg} \cdot \mathrm{m} / \mathrm{s})\end{array}$ & $\begin{array}{c}\text { Permanent } \\
\text { deflection } \\
\text { (transversal) } \\
(\mathrm{mm})\end{array}$ & $\begin{array}{l}\text { Initial } \\
\text { Speed } \\
(\mathrm{m} / \mathrm{s})\end{array}$ & $\begin{array}{c}\text { Momentum } \\
\text { transferred } \\
(\mathrm{kg} \cdot \mathrm{m} / \mathrm{s})\end{array}$ & \\
\hline \multirow{3}{*}{ Standard plate } & 1 & 38.2 & 1.712 & 78.886 & \multirow{3}{*}{37.43} & \multirow{3}{*}{1.736} & \multirow{3}{*}{79.7} & \\
\hline & 2 & 38.66 & 1.695 & 78.097 & & & & \\
\hline & 3 & 39.25 & 1.729 & 79.675 & & & & \\
\hline \multirow{2}{*}{ Back coated plate } & 1 & 36.78 & 1.715 & 79.718 & \multirow{2}{*}{36.5} & \multirow{2}{*}{1.739} & \multirow{2}{*}{80.54} & \\
\hline & 2 & 37.43 & 1.732 & 80.515 & & & & \\
\hline \multirow{2}{*}{ Front coated plate } & 1 & 37.07 & 1.778 & 82.58 & \multirow{2}{*}{36.7} & \multirow{2}{*}{1.803} & \multirow{2}{*}{81} & \\
\hline & 2 & 35.438 & 1,636 & 75.973 & & & & \\
\hline
\end{tabular}

If we neglect the last test, the permanent deflection of coated plates is roughly with $4 \%$ less than the deflection of uncoated plates even if the transferred moment is slightly higher. This result is a clear effect of the polyurea layer presence. In order to asses the efficiency of the aditional polyurea layer we use the theoretical curve proposed by Rotariu [18] that indicate the deflection reduction obtained for a virtual monolithic plate that keeps the mechanical properties and thickness of metallic component of metal/ polyurea bilayer and the areal density of the entire structure. The permanent deflection provided by Rotariu function [18], for tested configuration, is $11.3 \%$ less than nominal one. This indicates a less efficiency for real polyurea/steel bilayer in comparison to the virtual monolithic plate.

Experimental data were also used for a thorough assesment of numerical model accuracy. The global criteria that can be expressed by numbers, the transferred momentum and the maximum permanent deflection, are compared in table 2. Regarding the shape of the plate bulge produced by the impulsive load, the graphical method is the most proper way to show the numerical model accuracy. In figure 8 the experimental bulge profiles of the transversal section are compared to numerical results. There are no obvious differences between numerical results and experimental data.

A third cathegory of assesment criteria are the signals aquired by sensors and gauges: accelerations and overpressures. The accelerations were time integrated in order to get the velocity. Both, experimental and numerical velocity evolution are show for a time window of $40 \mathrm{~ms}$ for all three tested configurations in figure 9 . For first $5 \mathrm{~ms}$ the evolutions are quite similar for all three configurations. The discrepancy between the evolution of recorded signals, digital and experimentally, for time bigger than $5 \mathrm{~ms}$ can be explained due to simplified assumptions that were introduced in the numerical model. In numerical simulation, the entire structure was designed as a monolithic assembly: elements and clamping or clamping screws are neglected and the components were joined together to behave as a single body. Also, no vibration damping option was defined in numerical model.

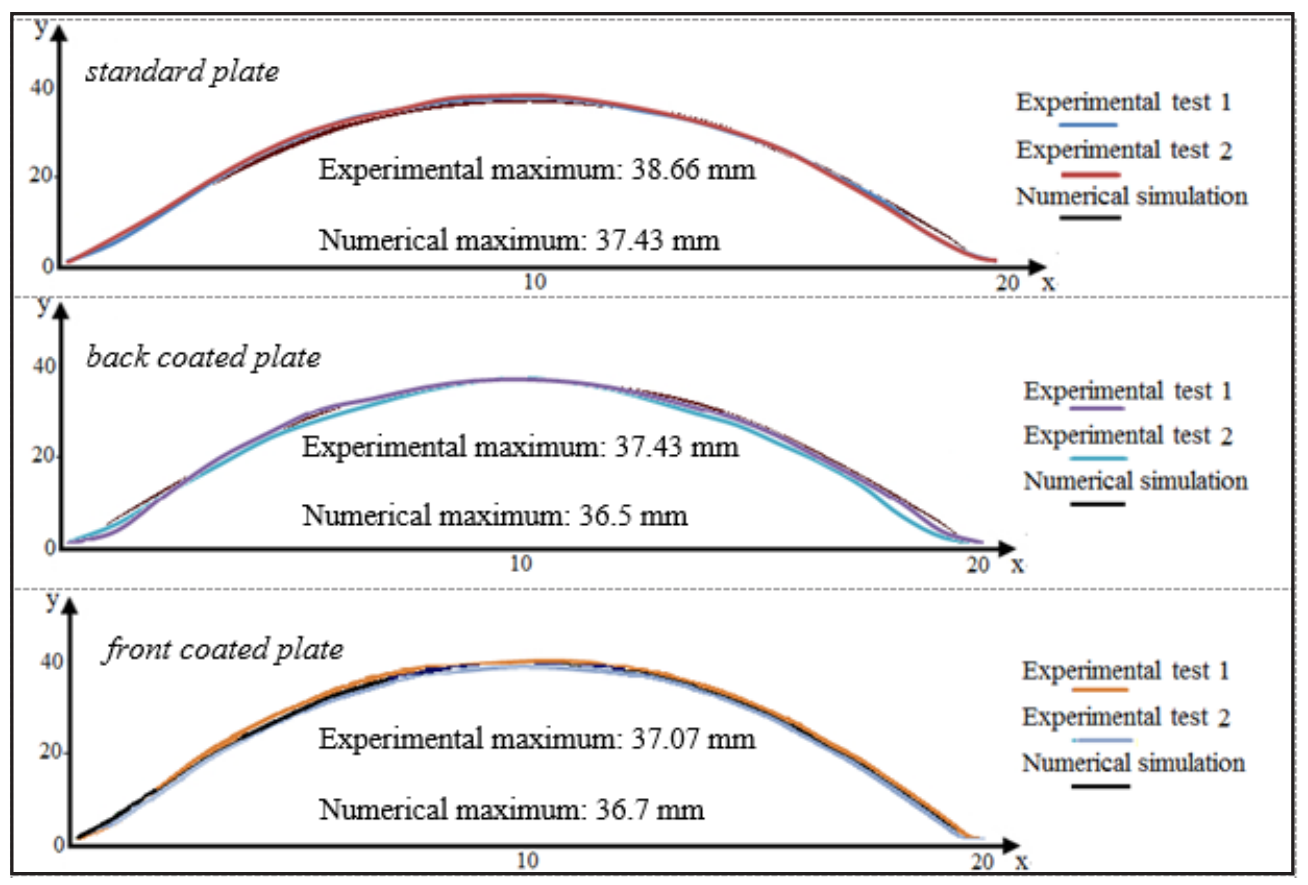

Fig. 8. Comparison of the cross-sectional profiles for analyzed configurations

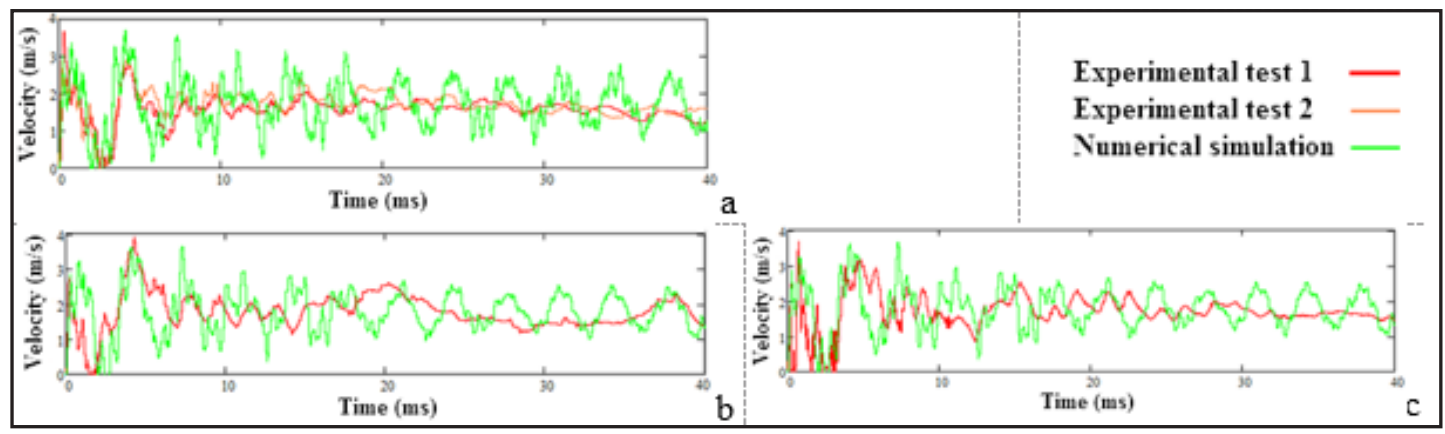

MATERIALE PLASTICE $\bullet 56 \diamond$ No. $3 \bullet 2019$ 


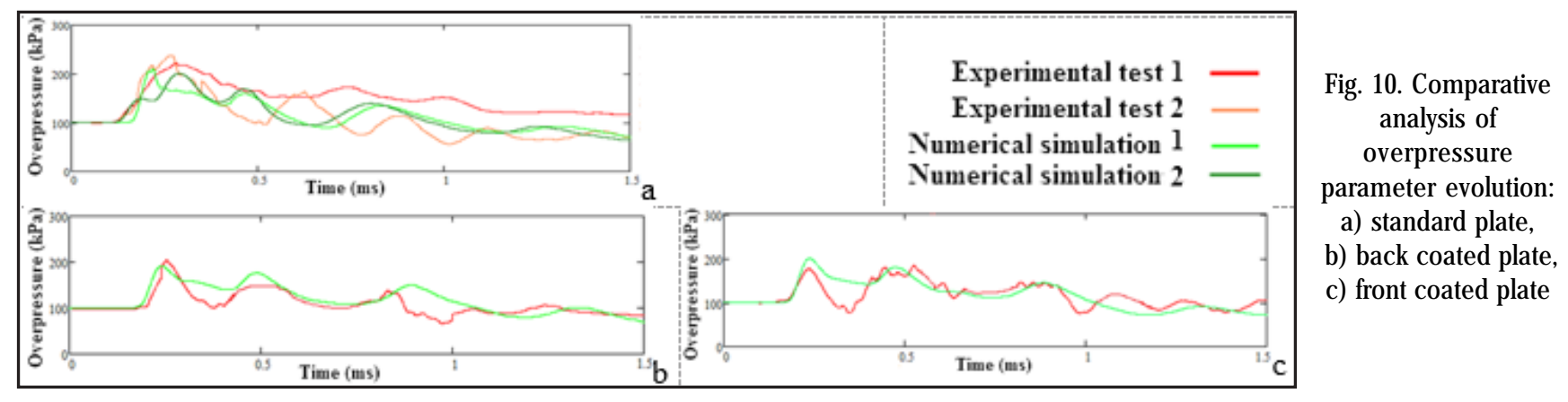

For a much shorter time window of $1.5 \mathrm{~ms}$ the overpressures are show in figure 10. The evolution of these signals is presented only for the first $1.5 \mathrm{~ms}$, because, after about $1.5 \mathrm{~ms}$ to $2 \mathrm{~ms}$, the shock wave surrounds the testbench, acting on the pressure transducer from many directions. Also, in real tests after the time $t=1.5 \mathrm{~ms}$ (the plate loading period), during the structure jump, the signal recorded by the pressure transducer is affected by the inertia of the system components. The maximum overpressure is above $200 \mathrm{kPa}$, for the bare plate and approx. $200 \mathrm{kPa}$, for coated plates.

The numerical simulations reveal the occurence of plastic hinge on the lateral bent edges of plates near to the blast wave source where the effective plastic strain reach comparable values to those obtained in the area of the permanent maximum deflection (Fig. 7), a reason to consider the lateral bent edges as vulnerable areas of plates. The plastic hinge are not so obvious in real tests (Fig. 8), partially because the right angle with no bent radius of virtual plate edge (shell elements) is not coresponding to the real configuration where the edge is obtained through real plate bending and partially because the nodes joint option not allow a relative movement between the plate lateral sides and rig components.

One unexpected information revelead by the simulations is related to the effective plastic strain deformation reach in the area of the permanentmaximum deflection. Despite the fact that the highest permanent maximum deflection is obtained for bare plate configuration, the highest effective plastic strain deformation, around $13 \%$, is reached for the front coated plate. This result indicates that the presence of a polyurea layer on the exposed surface it is not recomended, as long as can act as a factor that enables the steel plate failure.

The simulations also show that the considerable permanent deflections ( $\cong 40 \mathrm{~mm}$ deflection vs. $200 \mathrm{~mm}$ plate span) are obtain for effective plastic strain values relativelly smalls ( $10 \%)$ for which the strenght of polyurea is around $9 \mathrm{~N} / \mathrm{mm}^{2}$, corresponding to material characteristics from table 2, a considerable lower value than the specific OL50 steel yield stress.

\section{Conclusions}

Experimental studies on the behavior of shock-resistant protective materials mainly involves the generation of shock waves as a result of the detonation of explosive charges and the measurement of the effects characteristics on the structures tested according to the different experimental parameters.

The purpose of this study was to determine the ability to mitigate the effects of explosions by metal-elastomer bilayer configurations.

$1 / 6$ small-scale testing procedure based on military standard STANAG 4569 Level 3B, has showed its utility by giving useful information on the structure blast loading process through high-speed camera and sensors data recording and post-test measurements.

For a better insight of the blast wave/structure process the numerical simulations were used. The validity of numerical models building aproaches and materials models adopted was verified through a thorough comparison of real tests data with numerical results obtained by simulation (impulse transferred to the structure, plastic deformations, accelerations and overpressure).

The comparative analysis of the two sets of data reveals a satisfactory correlation between the experimental values and those determined numerically for the analyzed parameters.

Regarding bilayer configurations tested, there was not any significantimprovement in the behavior of the structure as a result of its presence in any of the proposed options. In both cases the bilayered plates have shown less promising results than the monolithic steel plates of the same areal density. Moreover, numerical simulations indicate that the presence of a polymer layer on the exposed surface it is not recomended, as long as can act as an amplification factor increasing the effective plastic strain in the region where the blast wave acts.

Acknowledgements: This work is supported by the project ANTREPRENORDOC, in the framework of Human Resources Development Operational Programme 2014-2020, financed from the European Social Fund under the contract number 36355/23.05.2019 HRD OP /380/6/13-SMIS Code: 123847.

\section{References}

1.GAMONPILAS, C., McCUISTON, R., Polymer, 53(17), 2012, p. 36553658

2.RAVI-CHANDAR, K., Experimental Characterization of Nonlinear Viscoelastic and Adhesive Properties of Elastomers - Report, University of Texas, 2006

3.***https://www.specialty-products.com

4.FEAGA, M., The effect of projectile strike velocity on the performance of polyurea coated RHA plates under ballistic impact - Dissertation, Lehigh University, 2007

5.AMINI, M.R., ISAACS, J ., NEMAT-NASSER, S., Mechanics of Materials, 42(6), 2010, p. 628-639

6.AMINI, M.R., Effect of polyurea on dynamic response and fracture resistance of steel plates under impulsive loads Dissertation, University of California, 2007

7.SHIM, J., MOHR, D., Int. J. of Plasticity, 27, 2011, p. 868-886

8.MATACHE, L., PUICA, C., ROTARIU, A., TRANÃ, E., BUCUR, F., Scientific Bulletin, Series D: Mechanical Engineering, 80(4), 2018, p. 153-162

9.NICA, G. B., LUPOAE, M., PAVEL, F., BACIU, C., Int. J. of Civil Engineering, 16(9A), 2018, p. 1125-1136

10.HADAR, A., CONSTANTINESCU, I.N., J IGA, G., IONESCU, D. S., Mat. Plast., 44, no. 4, 2007, p. 354-360

11.SARVA, SS., DESCHAMEL, S., BOYCE, MC., CHEN, W., Polymer 2007, 48(8), 2007, p. 2208-2213 
12.AMIRKHIZI, A.V., ISAACS, J., MCGEE, J., DE LAURISTON, N.L., NEMATNASSER, S., Sem. Proceedings on Experimental \& Applied Mechanics, 2005, p. 465-466

13.LEE ,Y.-W., WIERZBICKI, T., Int. J. of Impact Engineering, 31, 2005, p. $1253-1276$

14.SPRANGHERS, K., LECOMPTE, D., SOL, H., VANTOMME, J., Material characterization of blast loaded plates, $9^{\text {th }}$ National Congress on Theoretical and Applied Mechanics, 2012

15. BUCUR, F., TRANA, E., ROTARIU, A., GAVRUS, A., BARBU, C., GUINES, D., EPJ Web of Conferences, 94, no. 04044, 2015, DOI: 10.1051/ epjconf/20159404044.
16.BUCUR, F., Contributions to improve protection factor of military vehicles armor, Phd Thesis, Bucharest, 2015

17.ACKLAND, K., ANDERSON, C., NGO, T., Int. J. of Impact Engineering, 51, 2013, p. 13-22

18.ROTARIU, A., BUCUR, F., TOADER, G., LUPOAE, M., SAVA, A., SOMOIAG P., CIRMACI-MATEl, M.V., Mat. Plast., 53, no. 4, 2016, p. 670674

19.*** STANAG 4569 Protection Levels for occupants of Logistic and Light Armored Vehicles 20.***AUTODYN $®$ User's Manual

21.ZAKRISSON, B., Numerical and Experimental Studies of Blast Loading, Licentiate Thesis, Universitetstryckeriet, Luleå University of Technology, Ornsköldsvik, 2010

Manuscript received: 20.06 .2019 